\title{
Using Improved Power Electronics Modelling and Turbine Control to Improve Wind Turbine Reliability
}

\author{
Ting Lei, Mike Barnes, Sandy Smith, Sung-ho Hur, Adam Stock, and William Leithead
}

\begin{abstract}
Improving offshore wind turbine reliability is a key industry goal to improve the availability of this renewable energy generation source. The semiconductor devices in the wind turbine power converter (WTPC) are traditionally considered as the most sensitive and important components to achieve this, and managing their thermo-mechanical stressing is vital, since this is one of their principal long-term aging mechanisms. Conventional deterministic reliability prediction methods used in industrial applications are not suitable for wind turbine applications, due to the stochastic wind speed. This paper develops an electro-thermal model of the power devices which is integrated with a wind turbine system model for the investigation of power converter thermal cycling under various operating conditions. The model has been developed to eliminate the problems of PWM switching, substantially reducing simulation time.

The model is used to improve the current controller tuning method to reduce thermal stresses suffered by the converter during a grid fault. The model is finally used to design a control method to alleviate a key problem of the doubly-fed induction generator (DFIG) - severe thermal cycling caused during operation near synchronous speed.
\end{abstract}

Index Terms-Wind turbine power converter, Power device reliability, electro-thermal modelling, PSCAD/EMTDC

\section{INTRODUCTION}

$\mathrm{T}$ HE power converter as a subassembly of the wind turbine is subject to high failure rates, which makes it a major concern in the overall reliability of future offshore wind farm developments [1]. An industry survey [2] has revealed that the power semiconductor switch is most vulnerable to thermal cycling. It suffers two resultant principle failure mechanisms bond wire lift-off and solder fatigue. More accurate thermal cycling modeling of the semiconductor, and mitigation strategies for thermal cycling are thus important to improve wind turbine reliability. It is this which this paper addresses.

Reliability research for the WTPC has just been started [3].

Manuscript submitted September 20, 2014 for review. This work was supported in part by the Engineering and Physical Sciences Research Council under Grant EP/H018662/1 - Supergen Wind Energy Technologies".

T. Lei, M. Barnes and Sandy Smith are with the department of Electrical and Electronic Engineering, University of Manchester, M1 3DB, United Kingdom (e-mail: $\quad$ ting.lei@manchester.ac.uk; $\quad$ mike.barnes@manchester.ac.uk; mike.barnes@manchester.ac.uk).

W. Leithead, S. H. Hur, A. Stock are with the Department of Electronic and Electrical Engineering, University of Strathclyde, Glasgow, Scotland, G1 1XW, United Kingdom (e-mail: w.leithead@strath.ac.uk; sung.h.hur@strath.ac.uk; adam.stock@strath.ac.uk).
Previous industrial reliability-based models can use defined load cases. However, due to the unpredictable nature of wind speed, a number of researchers have adopted an integrated model and conduct numerical simulation. In [4] and [5], the wind turbine model is used in conjunction with the power device's reliability model. In this way, the turbine operating modes are be firstly transformed into electric variations, which are used to generate the device temperature variations by the electro-thermal model, and then are converted to lifetime consumption factors.

Relevant research in this area shows that both the synchronous and the rated operating speeds have been considered as the critical operating points [6], [7] and [8]. It is known that the device lifetime is related to both the mean temperature and its variations [5]. Working close to synchronous operating point is especially undesirable for a doubly-fed induction generator (DFIG) wind turbine, as the low frequency load current will cause large peak-to-peak temperature variations. Other literature investigates the impacts of different turbine control and converter control strategies [9] and [10], or various wind roughness [11]. An improved control method to reduce thermal stresses in three-level neutral-point-clamped (3L-NPC) converters has also been analyzed [12]. In previous research, a detailed electro-thermal model is usually not presented. Such a model involves a wide bandwidth range for different sub-systems, (from several $\mathrm{kHz}$ to a few $\mathrm{Hz}$ ), thus it should be designed with sufficient detail so as not to lose accuracy, but also be simplified in order to reduce the computational effort.

This paper presents an averaged electro-thermal model. A detailed description on how to calculate the power loss and the development of the thermal network are given in Section III and IV. Numerical simulation based on this model is conducted in PSCAD/EMTDC to investigate the device thermal cycling under different operating conditions, as is illustrated in Section V. Section VI presents the temperature variations under variable wind speeds with the rotor speed working near the synchronous point. It also discusses the significant enhancement achieved through using a modified turbine control strategy.

\section{MODEL INTEGRATION}

The interactions between different parts are illustrated in Fig.1 (a). The loss dissipation $P_{\text {loss }}$ is calculated according to 


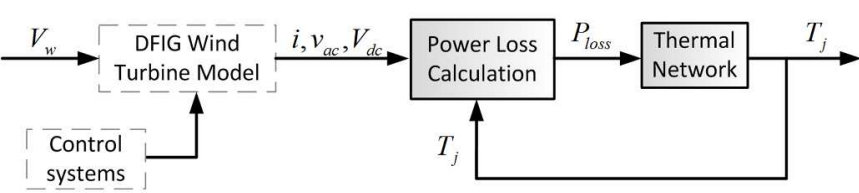

(a)

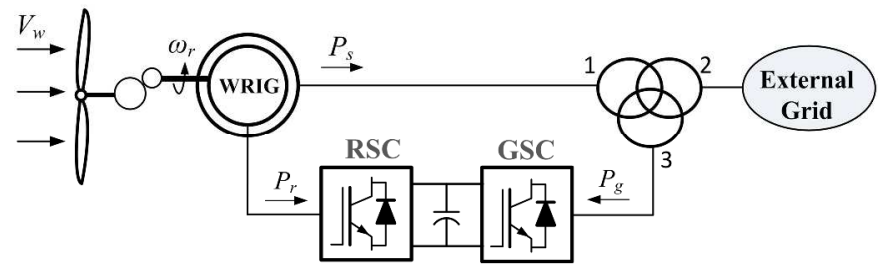

(b)

Fig. 1. Model Integration. (a) Interactions between the wind turbine model and the electro-thermal model, (b) DFIG wind turbine electro-mechanical system model.

the averaged electrical signal from the wind turbine (current $i$, ac voltage $v_{a c}$ and dc-link voltage $V_{d c}$ ) and the junction temperature $T_{j}$. This is then used by the thermal network to predict the temperature variations.

A coherent electro-mechanical wind turbine model was established, as in Fig.1 (b). It consists of an aerodynamic model that converts the wind energy into aerodynamic torque and a 2-mass shaft system that can reflect the mechanical oscillations when it is subject to disturbances. These together with the wind turbine control are developed in MATLAB, from which the electro-mechanical parameters can be extracted and applied to the DFIG control level. A DFIG machine, a switch-averaged voltage source converter and the converter control system are built in PSCAD/EMTDC, which is described in detail in [13] and will not be repeated here.

The work here is to establish the electro-thermal model and to work out the impacts on the reliability via the model integration. The rest of the paper will present the approach to model and the analysis of thermal cycling in different conditions.

\section{POWER LOSS CALCULATION}

Generally, there are two types of model used to calculate the semiconductor's power loss. The first is an analytical model, by which the average loss of a load cycle can be delivered [14], [15], [16] and [17]. The other is a numerical circuit model, from which the instantaneous power loss is obtained in the form of pulse patterns [18] and [19]. The former is very fast, but the results will not reflect the instantaneous load variation; whereas the latter may take a very long simulation time as it needs a very small time step to detect the PWM switching. As the time constant of the thermal network is much larger than the PWM frequency, the output temperature is mainly affected by the fundamental load current variation, rather than the high frequency switching component. In this paper, a switch-averaged loss calculation method is thus adopted, where the average loss per switching cycle is determined as a function
TABLE I

PARAMETERs Used for CALCUlating THE SWITChING ENERGy [21]

\begin{tabular}{lcc}
\hline \hline & IGBT & Diode \\
\hline$K_{i}$ & 1 & 0.6 \\
$K_{v}$ & $1.3-1.4$ & 0.6 \\
$T C_{E S W}$ & $0.0031 / \mathrm{K}$ & $0.0061 / \mathrm{K}$ \\
\hline \hline
\end{tabular}

$K_{i}=$ current dependency exponents, $K_{v}=$ voltage dependency exponents, $\mathrm{TC}_{\mathrm{ESW}}=$ temperature coefficient, $\mathrm{K}=$ Kelvin

of the load current. In the following, basic equations for obtaining conducting and switching losses are described.

\section{A. Conduction Loss}

In [18], a fast numerical simulation method is proposed for calculating the conduction losses $P_{c o n}$. It uses the characteristic curves provided in the manufacturer's datasheet to derive a second order polynomial function (1), with the load current $I_{L}$ and device temperature $T_{j}$ as the input variables.

$$
P_{\text {con }}\left(I_{L}, T_{j}\right)=\left(a_{0}+a_{1} T_{j}\right) I_{L}+\left(b_{0}+b_{1} T_{j}\right) I_{L}^{2}
$$

Here the coefficients $a$ and $b$ are obtained by curve fitting. The Semikron IGBT module SKiiP 2013 GB172-4DW [20] with $1.7 \mathrm{kV}$ blocking voltage and $2 \mathrm{kA}$ nominal current, which is designed for wind turbine applications, will be used for the purpose of developing the electro-thermal model of the power devices used in a 5MW DFIG wind turbine. The mechanical/electrical parameters of the wind turbine, the thermal impedances and the temperature coefficients $a$ and $b$ are given in the Appendix.

\section{B. Switching Loss}

The switching losses for a power device include turn-on and turn-off losses. For a diode, turn-off loss is also referred to as the reverse-recovery loss, which accounts for $99 \%$ of the total switching loss [21]. The energy generated during a switching event is given by (2) [22]. Here the switch-on and switch-off losses are added into a single switching event. It can be seen that several parameters affecting this loss type are: the blocking voltage $V_{C C}$, which equals to the dc-link voltage, the load current $I_{L}$ and the device junction temperature $T_{j}$. The superscript ' $r e f$ ' denotes for the reference values for the quantities, which is given in the manufacturer's datasheet. $K_{i}$ and $K_{v}$ are current and voltage dependency exponents; $T \mathrm{C}_{E S W}$ is the temperature coefficient. Typical values for these parameters used in this application are given in Table I.

$$
E_{S W}=E_{S W}^{r e f} \cdot\left(\frac{I_{L}}{I_{L}^{r e f}}\right)^{K i}\left(\frac{V_{C C}}{V_{C C}^{r e f}}\right)^{K v}\left(1+T C_{E s w} \cdot\left(T_{j}-T_{j}^{r e f}\right)\right)
$$

\section{Switch-averaged Loss Model}

As the switching frequency is much larger than the fundamental frequency, using a different modulation scheme makes little difference in the temperature dynamics. Also, the 


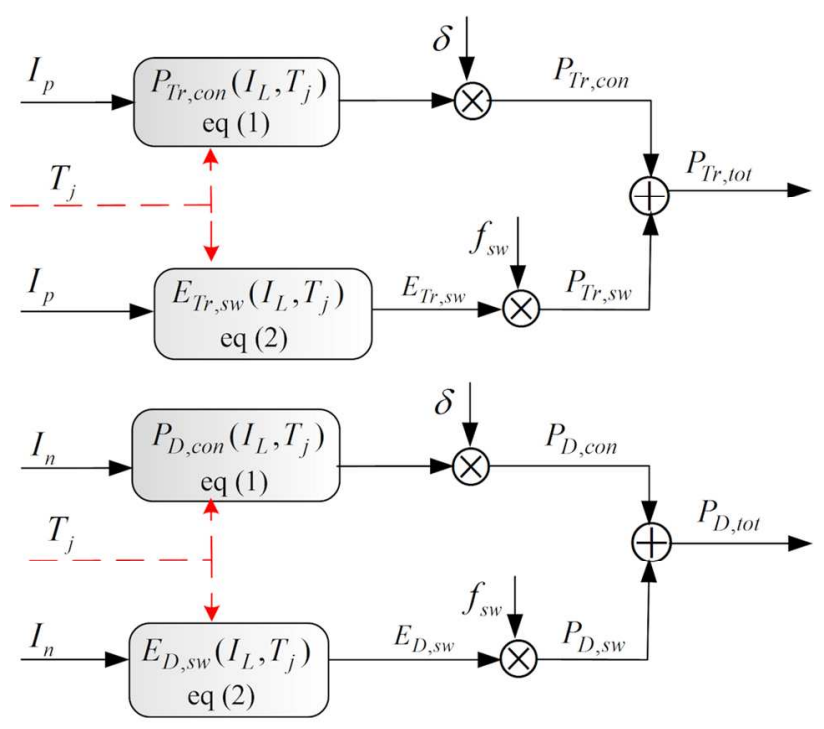

Fig.2. Schematic diagram of switch-averaged loss calculation model.

current can be considered as constant during one switching cycle. Then the conduction loss averaged for one switching cycle $P_{c o n}$ is related to the instantaneous conduction loss $P_{\text {con, ins }}$ as

$$
\begin{aligned}
& P_{\text {con,ins }} \cdot \delta \cdot \tau=P_{c o n} \cdot \tau \\
\Rightarrow & P_{\text {con }}=P_{\text {con, ins }} \cdot \delta
\end{aligned}
$$

Here $\delta$ is the duty ratio. For PWM with sine-wave carrier, the duty ratio can be expressed as a function of the dc-link voltage and the instantaneous phase voltage $v_{p h}$ [23].

$$
\delta=\frac{1}{2} \times\left(1+\frac{v_{p h}}{V_{d c} / 2}\right)
$$

The loss calculation method is illustrated in Fig.2, where the upper IGBT and the opposite lower diode are conducting for
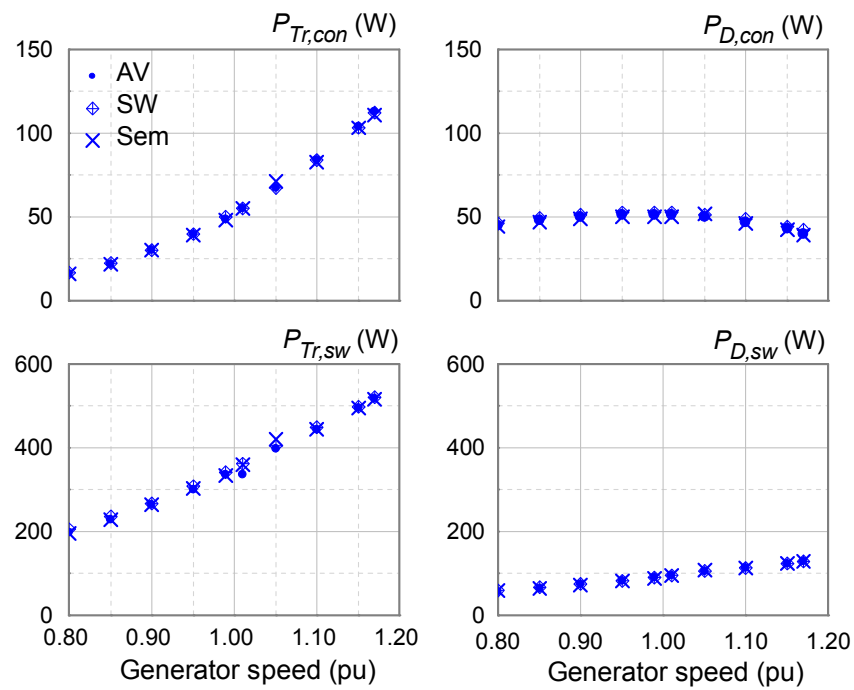

Fig. 3. Model verification with detailed PWM switched model and commercial software calculation (1 pu is the synchronous speed of the DFIG machine).

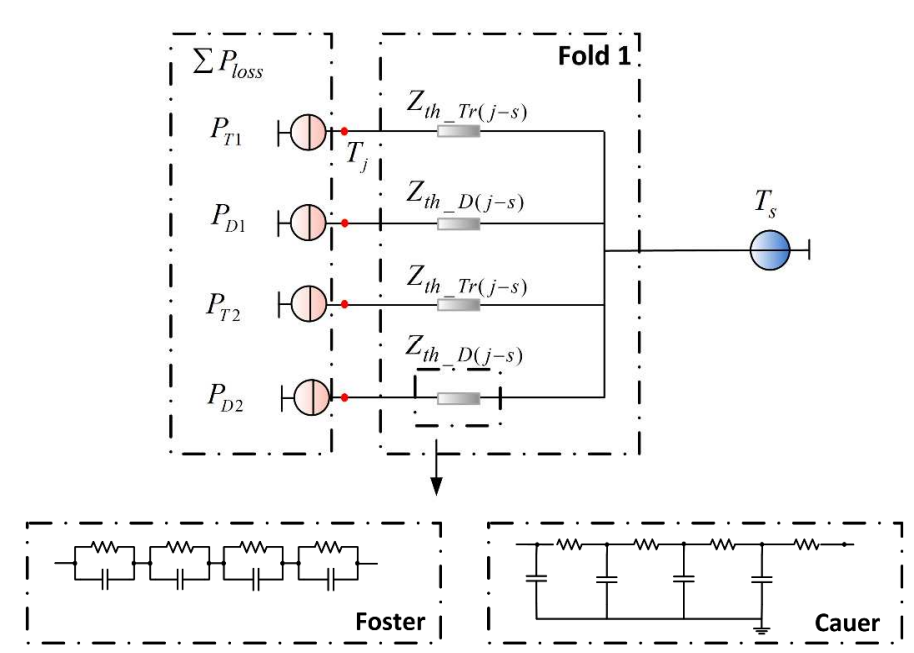

Fig.4. Thermal network of one 'fold' IGBT with heat-sink temperature modelled as constant value.

half a load cycle, thus $I_{p}$ and $I_{n}$ in (5) are used respectively. The subscripts ' $T r$ ' and $D$ denotes the IGBT transistor and the diode. The switching frequency $f_{s w}$ is $4.5 \mathrm{kHz}$. Combining eq. (1) - (5), the total losses are obtained at the output.

$$
I_{p}=\left\{\begin{array}{ll}
\left|I_{L}\right| & \text { if } I_{L}>0 \\
0 & \text { if } I_{L}<0
\end{array} \quad I_{n}= \begin{cases}0 & \text { if } I_{L}>0 \\
\left|I_{L}\right| & \text { if } I_{L}<0\end{cases}\right.
$$

Simulation time is substantially reduced by eliminating the PWM switching, while the transient characteristics of the load variation are preserved. As seen from Fig. 3, the averaged loss model (AV) is compared with two other different loss models: the conventional PWM switched model (SW) and the commercial software Semisel (Sem). The switched model with the power losses has been presented by a previous paper [24]. The manufacturer software SemiSel developed by Semikron is used to generate the mean loss values based on the user-input information such as the power flow, dc-bus voltage, rms ac voltage and current [22]. The dynamic losses obtained by model simulations are averaged for a load cycle in order to obtain the mean loss values. This can then be compared with the result of 'Sem' at different rotor speeds ( $0.8 \mathrm{pu}$ to $1.2 \mathrm{pu}$ ). As seen in Fig.3, the three sets of results match well. This indicates the accuracy of the fast switch-averaged model.

\section{THERMAL NETWORK}

\section{A. Fundamental Theory of Thermal Model}

Generally, the thermal characteristics of a solid system can be described by two alternative equivalent circuits composed of resistances and capacitances, as shown in Fig. 4. In this circuit, the current resembles the power dissipation, and the voltage resembles the temperature.

The Foster network (also referred to as a 'chain' type model) is constructed from purely a mathematical point of view, with each RC cell corresponding to a particular time constant of the transient impedance; while the Cauer network (also referred to as a 'ladder' type model) is built from a physical point of view, where each node indicates an actual physical position in the 


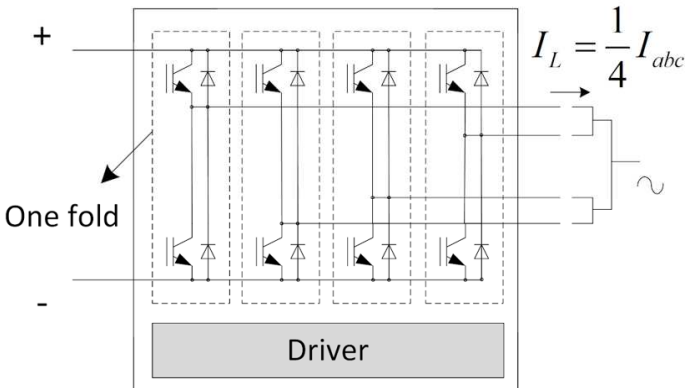

Fig. 5. Circuit construction of a half bridge SKiiP module.

solid system. In this topology the thermal resistance $R_{t h}$ is related to material conductivity and dimensions while the thermal capacitance $C_{t h}$ is related to heat storage capacity [25].

\section{B. SKiiP Module}

The thermal network for the SKiiP IGBT module has been established according to the manufacturer's datasheet. The power module is a half bridge inverter, with four IGBT legs (folds) connected in parallel, as shown in Fig.5. Each IGBT fold is mounted on a separate ceramic substrate. The four IGBT folds share a common heat-sink. The current passing through each device is a quarter of the total load current.

\section{Circuit Transformation}

As the Foster network has no real physical meaning, it cannot predict the temperatures at the layer interfaces, which are critical for identifying hot spots and improving design. Also, the Foster circuits cannot be cascaded to represent the thermal impedance of the entire system. e.g., combining the Foster circuits of the semiconductor and the heat-sink gives incorrect dynamic temperatures. Although constant heat-sink temperature can be assumed in most cases when analyzing the thermal cycling, for longer load changes, such as system start-up and a change of electrical demand, it is essential to model the entire thermal impedance from ambient to the chip. Quite often in a manufacturer datasheet, only a Foster network is provided due to the convenience with which parameters can

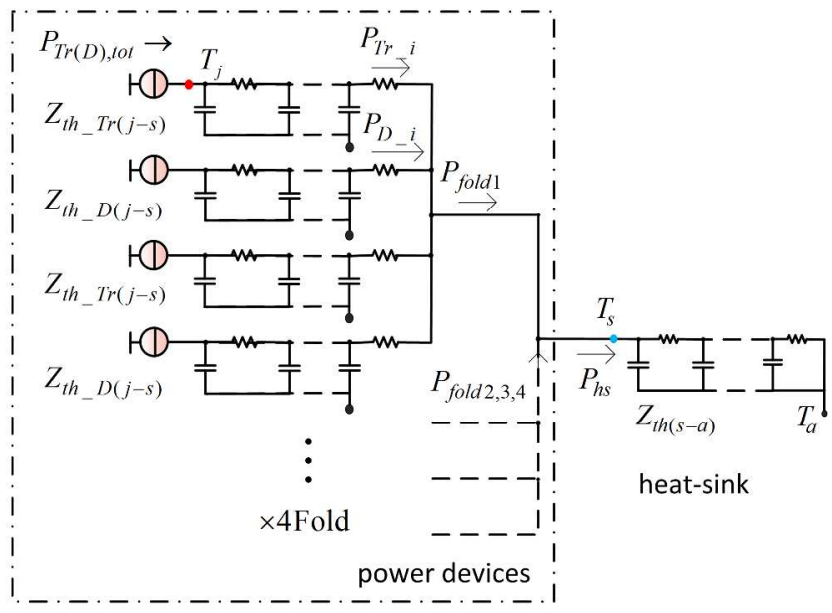

Fig. 6. Device-heat sink combined thermal network of a SKiiP module.
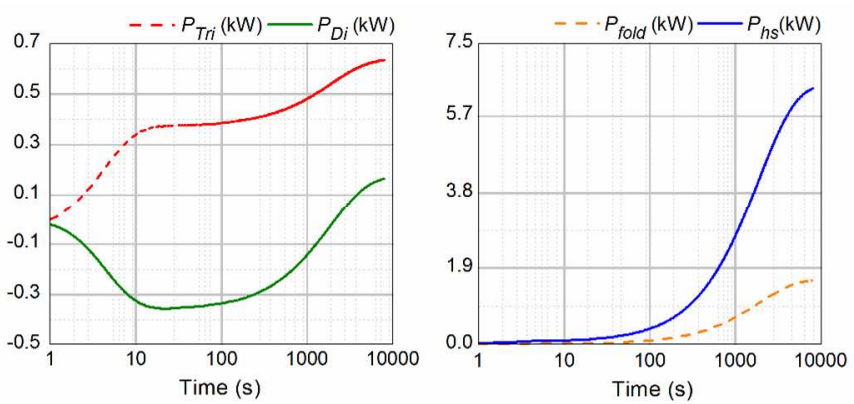

Fig.7. Loss dissipations in the power module during system start-up simulated with the complete Cauer circuit.

be derived from testing. Therefore, it is necessary to perform a circuit transformation to obtain the equivalent Cauer circuit.

Different ways have been proposed to derive the Cauer thermal network. A 3-D FEM method in combination with time constant analysis has been discussed in [26], which can deliver a Cauer model accurately representing the physical layers. This paper adopts a fast transformation method described in [27]. The individual Cauer circuits for IGBT, diode and heat-sink are derived and then combined together to get the complete thermal network of a converter. A brief introduction of this method is given here. Let the impedance seen from the $i$ th node represented by $Z_{t h i}$, and then it's relationship with $Z_{t h i+1}$ can be described as

$$
\frac{1}{Z_{t h_{-} i}(s)}=s \cdot C_{t h_{-} i}+\frac{1}{R_{t h_{-} i}+Z_{t h \__{-} i+1}(s)}
$$

Meanwhile, the impedance in a Foster circuit can be decomposed in the following form

$$
\frac{1}{Z_{\text {th_i } i}(s)}=\frac{D_{i}(s)}{N_{i}(s)}=a_{i} s+b_{i}+\frac{R_{i}(s)}{N_{i}(s)}
$$

where $R_{i}(s)$ is the remainder of the decomposition. By comparing the corresponding terms in (6) and (7), the Cauer circuit can be solved as

$$
\begin{aligned}
& C_{t h_{-} i}=a_{i} \\
& R_{t h_{-} i}=1 / b_{i} \\
& Z_{t h_{-} i+1}=-\frac{R_{i}(s)}{b_{i}^{2} N_{i}(s)+b_{i} R_{i}(s)}=\frac{N_{i+1}(s)}{D_{i+1}(s)}
\end{aligned}
$$

Assuming that the number of nodes in the Cauer circuit is ' $n$ ', this transformation will be repeated until $Z_{t h \_n} \equiv 0$.

Fig.6 shows combined Cauer network of a SKiiP module. The device power losses obtained in Section III are used as inputs for each circuit branch. Here the thermal losses via radiation or convection are neglected. $P_{T r i}$ and $P_{D i}$ denote the losses flowing through the bottom of IGBT and diode; $P_{\text {fold }}$ is the loss through the ceramic substrates; the total loss transmitted to the heat sink is $P_{h s}$. The dynamic responses of these quantities during a system start-up are shown in Fig.7. It is observed the heat transmission is gradual and it can take an hour or more to finally reach steady state. Owing to the ladder type connection of the RC cells, a substantial amount of heat will firstly flow into the grounded thermal capacitances before 
the temperatures reach the steady state. Hence the time constant for this combined Cauer model is much larger than that of the device or the heat sink. However, if a combined Foster circuit is used, the chain type RC cells will transmit the entire heat to heat sink instantaneously at the start, giving incorrect dynamic responses. This is why a Cauer model is preferred.

It is found that for the diode, the heat is not transmitted from the device to the heat-sink until after approximately 2000s. This is due to the diode's relatively larger time constant compared to the IGBT, thus the losses from the IGBTs make the heat sink temperature rise beyond the diodes' substrate temperature in a short period at the system start-up.

\section{IMPLEMENTATION WITH WIND TURBINE MODEL TO Evaluate The DeVice THERMAL CYCLING}

\section{A. Steady-state Thermal Cycling}

Although the heat-sink can significantly influence a long term temperature variation such as system start-up, for short term dynamic behaviors in a load cycle, its effect is negligible. Therefore a constant temperature heat-sink is used for steady state analysis.

The average temperature of the IGBT and the heat-sink with corresponding variations $\Delta T_{j}$ resulting, are recorded for a range of rotor speeds in Fig. 8. It can be observed that the mean temperature rises rapidly as the rotor speed increases to the rated value, with a maximum steady state temperature approaching $120^{\circ} \mathrm{C}$. It is reported in [22] that the stress factor of semiconductor increases little with temperature when it is below $125^{\circ} \mathrm{C}$, however, the device deteriorates very quickly when the temperature is above $125^{\circ} \mathrm{C}$. The presented model indicates that working at rated operating point generally imposes little harm for this WTPC; however, it is vulnerable to abnormal events such as transients change in the load current (increase torque demand or grid fault, which will be discussed later). The converter lifetime may be significantly reduced if that frequently happens during a full load condition.

The Coffin-Manson-Law [3] indicates that both the mean temperature and temperature variations affect the

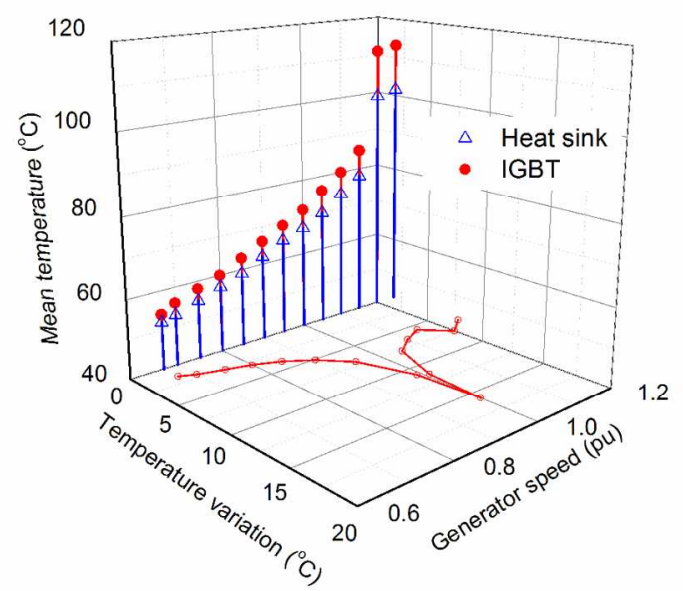

Fig. 8. Mean temperature and variations at different rotor speeds.

semiconductor's life time, i.e. the number of cycles to failure. For a DFIG wind turbine, working with a small slip frequency
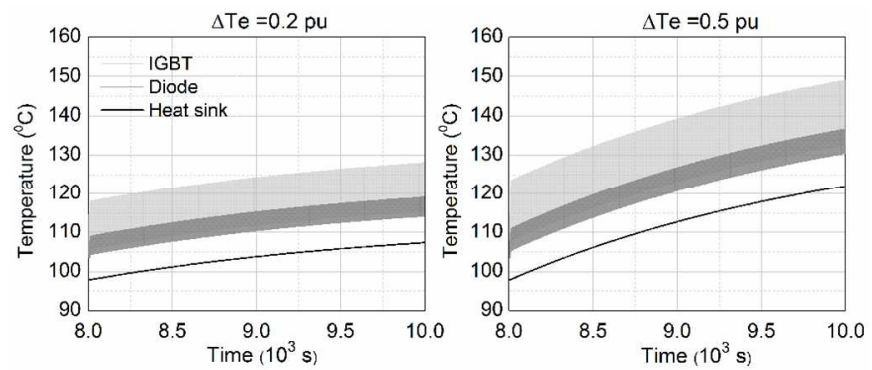

Fig. 9. Temperature responses to a step change in electric torque.

causes long time temperature rises and falls and thus produces large peak to peak variations, resulting severe stresses in the semiconductors. It is reported in [7] that for the converter, the most stressful slip range around the synchronous point is approximately $0.2-0.4 \mathrm{~Hz}$.

\section{B. Electric Torque Overload}

The wind turbine initially was simulated with a nominal rotor speed and at its full load. Then step increases in the torque demand were applied at the DFIG. The dynamic temperature responses of IGBT, diode and heat sink are shown in Fig.9 for more than 30 minutes after the torque step. Two representative cases are illustrated. In the case of 0.2 pu torque overload, Fig. 9 (left), the power device can work well without significant deterioration for approximately 7 minutes. In the case of $0.5 \mathrm{pu}$ torque overload, the power device more quickly reaches a temperature where some lifetime deterioration occurs but it can still operate up to half an hour to its limit temperature of $150^{\circ} \mathrm{C}$, Fig. 9 (right).

It can be observed that the power converters' overload duration time is very long owing to the effective water-cooled heat sink. However, this does not take account of other abnormal conditions such as load disturbances or grid-faults, in which case the heat-up process may be accelerated and overload survival time for the power devices will be reduced.

\section{Grid Voltage Drop}

The wind turbine model was initially taken to its rated operating point, and is connected to a strong grid with constant frequency and voltage during the normal unfaulted operational condition A 40\% three-phase balanced voltage drop was then introduced for $0.5 \mathrm{~s}$. Constant heat sink temperature was considered again as the fault duration is very short. Vector control is implemented in the DFIG control level, as is illustrated in Fig. 10 (a). For the RSC control, the stator reactive power $\mathrm{Q}_{\mathrm{s}}$ and the electric torque $\mathrm{T}_{\mathrm{e}}$ are independently controlled by the rotor current components $i_{r_{-} d}$ and $i_{r_{-} q}$, which will be physically determined by the rotor voltage $\mathrm{V}_{\mathrm{r}_{-} \mathrm{d}}$ and $\mathrm{V}_{\mathrm{r}_{-} \mathrm{q}}$. Similarly, the grid reactive power $\mathrm{Q}_{\mathrm{g}}$ and the DC voltage $\mathrm{V}_{\mathrm{dc}}$ are controlled by the GSC using $i_{g_{-} d}$ and $i_{g_{-}}$.

The three phase currents and the junction temperatures of both the RSC and GSC are presented in Fig.10 (b). The left graphs show results when both the d-q current loops of the RSC are set at $10 \mathrm{~Hz}$. Two behaviours of the rotor current caused by the fault are presented, which will affect the device temperature. The first is the large transients as the fault starts and fault clears. This is due to the electromagnetic current component induced by the grid voltage drop. The other is a larger rotor current 
shown during the fault condition. This is a result of the RSC
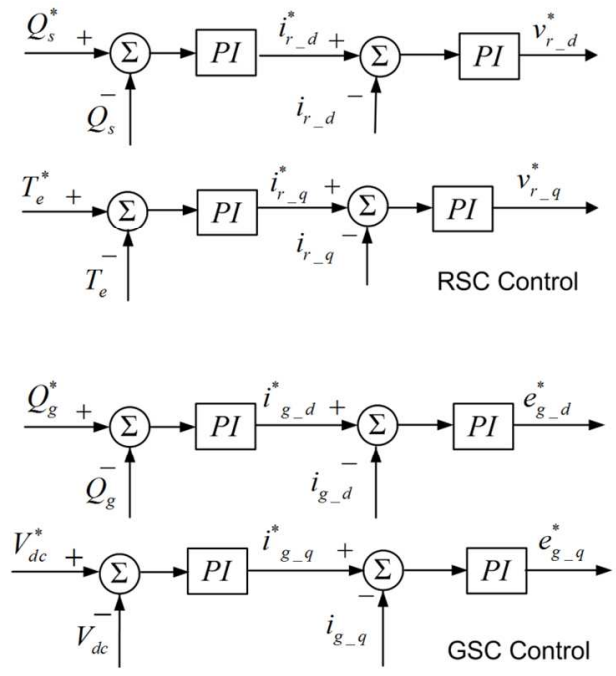

(a)
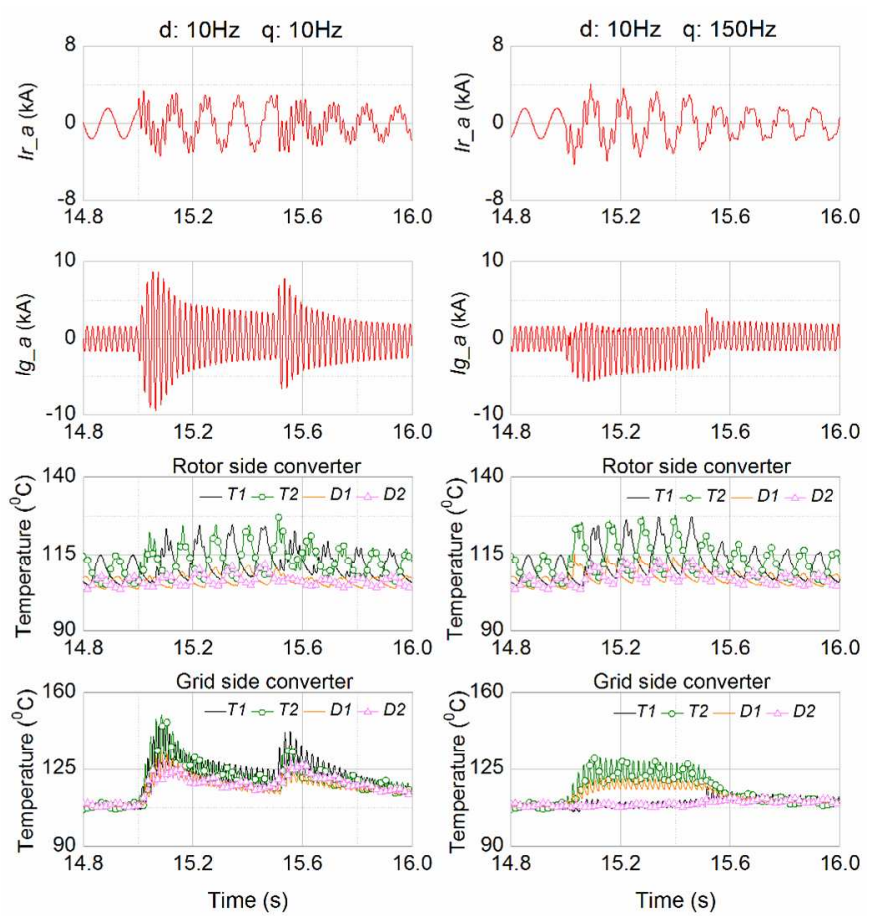

(b)

Fig.10 Electro-thermal behaviors during grid fault, (a) DFIG converter control strategy, (b). Currents and temperatures in a $40 \%$ grid voltage drop.

controller trying to compensate the reduction in power flow.

In the right set of graphs, the active power control (q-loop) is set at a higher bandwidth, $150 \mathrm{~Hz}$. Using a faster q-controller itself effectively reduces the transients that are mainly generated in the active control loop. Therefore, it is not necessary to increase the bandwidths in both loops as this may cause instability. Based on thermal requirements, careful re-tuning of controllers is thus helpful. The modified controller reduces the current transients, which improves the GSC thermal stresses. The peak temperature is reduced from $150{ }^{\circ} \mathrm{C}$ to $130^{\circ} \mathrm{C}$. The diode's temperature swing is smaller than the IGBT due to a relatively larger thermal constant.

\section{Synchronous PoInt ENHANCEMENT THROUGH THE MODIFIED TURBINE CONTROL}

\section{A. Dynamic System Behaviors at Synchronous Speeds}

The wind turbine dynamic behaviors around the synchronous operating speed were analyzed by employing a variable wind profile. Firstly simulations were carried out using a generic control strategy, where the optimum electric torque characteristic (cubic Bezier curve) was tracked. In Fig.11 the simulation was run for 800 s from 6200s (after starting up and reaching a steady state). The top graph depicts the applied wind profile, with $8.8 \mathrm{~m} / \mathrm{s}$ average speed and $10 \%$ turbulence. The second graph shows the rotor speed variation, and the third graph shows the temperature variations of a single phase's power devices and the common heat sink. It can be seen that the heat-sink temperature is not changed significantly $\left(1.5^{\circ} \mathrm{C}\right)$ during the entire simulation time. Device temperature swing reaches a peak value whenever the rotor speed passes across the synchronous point. This is because of the slow (slip frequency) currents flowing in the rotor side converter. A magnified view of the first selected zone $S_{1}$ is shown in the bottom graph of Fig. 11, which allows a more detailed observation. The upper IGBT and lower diode, which in this particular case conduct more current, are subjected to more thermal stresses than the other devices. This uneven heat distribution lasts about $10 \mathrm{~s}$ with the largest temperature excursion rising above $15^{\circ} \mathrm{C}$.
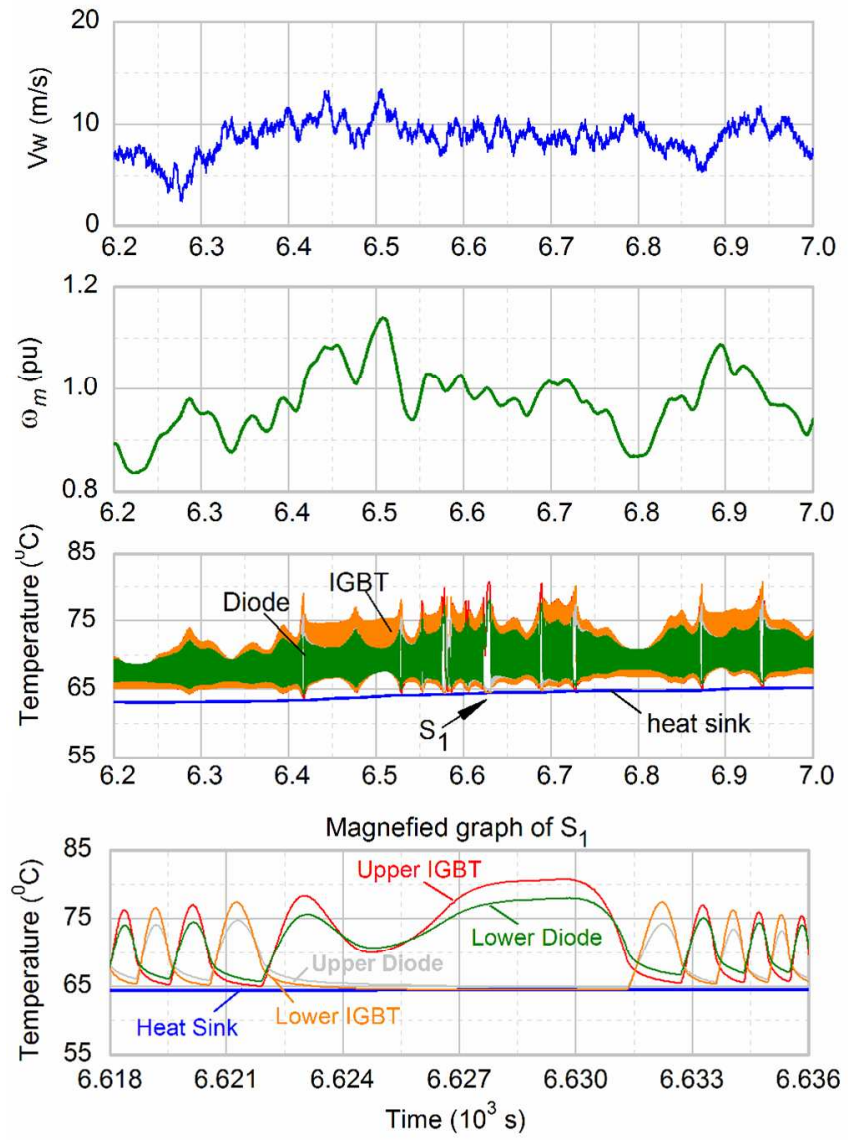

Fig.11. System dynamic responses under $10 \%$ wind turbulence using the generic controller. Lowest trace is a magnification of S1 zone in third trace down 


\section{B. Enhancement through a Modified Controller}

A modified control strategy is introduced to this model that regulates the wind turbine to avoid long-period operation near the synchronous speed. A similar method was introduced in [28] to prevent the excitation of structural resonance. The method used in [28] has been adapted and structured to avoid the undesirable operating point around synchronous speed for extended operation, to avoid the protracted thermal cycling which would result. As shown in Fig.12, the generic torque optimum curve will be interrupted around the synchronous point $(104.7 \mathrm{rad} / \mathrm{s})$. The wind turbine will track the new curve A1 - A5 when the rotor speed is rising from below synchronous to above synchronous speed and B5 - B1 when speed is decreasing. The purpose is to avoid a range of set frequencies (with a range of approximately $1.4 \mathrm{~Hz}$ slip frequency) during the wind turbine's normal operation. The frequeneies are tsed as demonstration to show the effectiveness of implementing this method. As seen in the Fig.12, when the wind speed increases from $8 \mathrm{~m} / \mathrm{s}$ to $9 \mathrm{~m} / \mathrm{s}$, the whole control process involves four procedures: from $\mathrm{A} 1$ to $\mathrm{A} 2$, the electric torque demand increases quickly, counteracting the rotor speed's acceleration; when it exceeds the peak value (A2), the torque demand will drop quickly to assist with the rotor speed's acceleration; from A3 to A4, the slope reduces to avoid a large overshoot; from A4 to A5, the torque demand converges with the mechanical torque at $9 \mathrm{~m} / \mathrm{s}$ wind and a new balance point is established. Similar procedures are followed when the wind speed drops and the controller switches from B1 to B5.

When the controller is switching from $\mathrm{A} 2$ to $\mathrm{A} 4$, there will be no problem if the wind speed is inereasing, sinee the larger mechanical torque will contribute to the controller switching process. However, if the wind speed is decreasing morequiekly than the switch takes place, the corresponding mechanieal torque will drop below the electric torque, and the rotor speed would return to a point on the curvesmaller than $\omega_{r, A 2}$ eausing ehattering. One important thing to successfully implement this

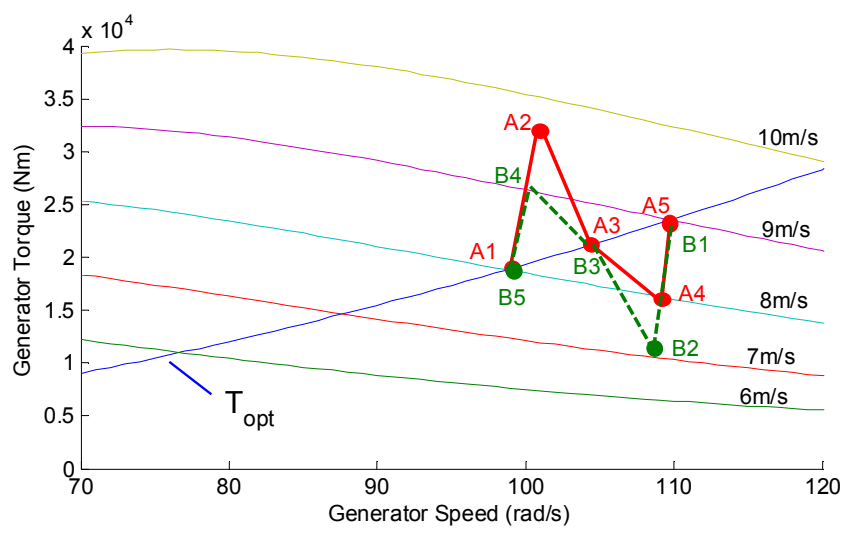

Fig.12. Generic and modified wind turbine control strategies.

strategy is that the controller needs to switch from A2 to A4 (or B2 to B4) more quickly than the wind speed is likely to change to avoid chattering. It is reported in [29] that the maximum rate of change of wind speed is approximately $m_{10}=0.11 \mathrm{~m} / \mathrm{s}^{2}$ for turbulence intensities (TI) of $10 \%$. Considering the worst
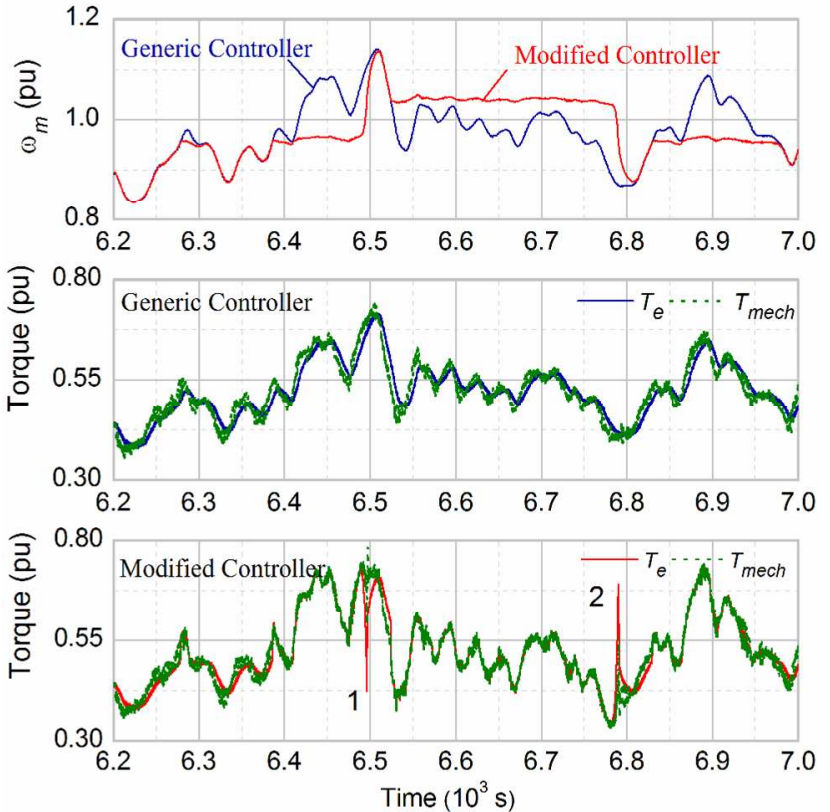

Fig.13. Comparison between the generic and the modified controller performances in rotor speed, electrical and mechanical torque responses.
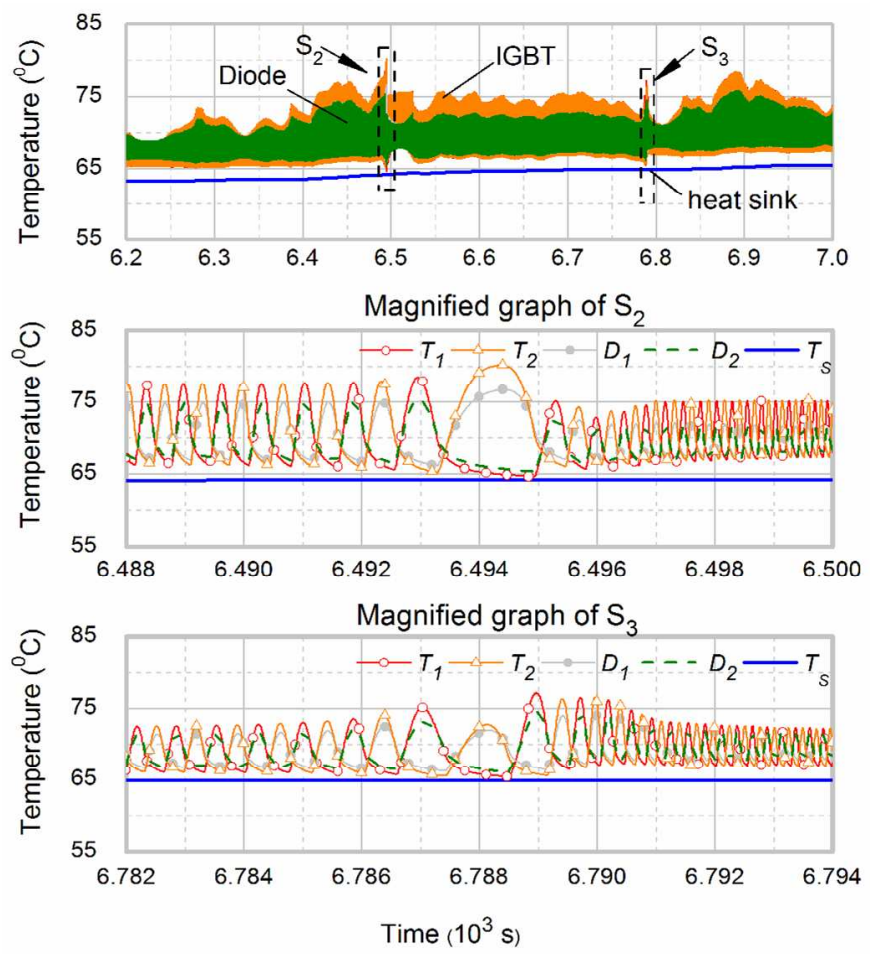

Fig.14. Dynamic temperatures of a single phase converter devices with magnified views at two switching points S2 and S3.

scenario, where the wind speed is decreasing from approximately $9.5 \mathrm{~m} / \mathrm{s}\left(v_{w, A 2}\right)$ to $8 \mathrm{~m} / \mathrm{s}$ or lower $\left(v_{w, A 4}\right)$, then maximum time used for the generator speed to switch from $\omega_{r, A 2}$ to $\omega_{r, A 4}$ is

$$
t=\frac{v_{w, A 2}-v_{w, A 4}}{m_{10}}
$$

The modified controller will force the generator speed to stay with a defined slip frequency or to pass the critical region quickly when the wind speed rises or drops. Fig. 13 shows the 
Matlab simulations of a $5 \mathrm{MW}$ wind turbine's electrical and mechanical responses using both the generic and the modified controllers. The modified controller has effectively made the rotor speed (top graph) avoid the undesired operating region. There are two transients in the electric torque, the first one corresponds to the switching path $\mathrm{A}$ and the second corresponds to switching path B in Fig. 12.

The dynamic temperatures of the power devices using the new controller are simulated as shown in Fig. 14, where the magnified views of the switching transients $S_{2}$ and $S_{3}$ are presented as well. Comparing the modified controller with the generic controller (Fig.11), the number and the duration of large temperature pulsations are significantly reduced. It is shown that both the switching events take place within 2 seconds. This mitigates the deterioration of a particular device caused by uneven heat distribution. As a penalty, the torque to achieve this is increased during this period (labeled 1 and 2 in the bottom trace of Fig. 13). This illustrates a fundamental issue: if less time is to be spent in a given region, greater manipulated input is required to move the system operating point rapidly through this zone.

\section{CONCLUSION}

In this paper, a complete converter electro-thermal network with switch-averaged loss prediction model is presented. The accuracy of the model has been verified with the conventional PWM switching model and manufacturer's software. This method allows a larger time step without degrading the accuracy and hence substantially increases the simulation speed.

Near the synchronous operating point, large temperature swings impose significant shear stress at the semiconductor layer interfaces. A modified wind turbine control strategy is implemented on the model, which shows that the large temperature excursions in the RSC can be reduced.

The contributions of this paper are the integrated dynamic electro-thermal model, highlighting the impact of electrical control tuning and evaluating performance integration with conventional and new turbine control. Future work can be extended to involve a lifetime model. Given the practical operating condition, the impacts of using different control schemes as well as operating conditions on the device lifetime consumption should be evaluated.

\section{APPENDIX}

TABLE A.1

THERMAL IMPEDANCES OF FOSTER NETWORK

\begin{tabular}{llccccc}
\hline \hline & $R_{t h}$ & $\tau_{T r}$ & $R_{t h_{-} D}$ & $\tau_{D}$ & $R_{t h_{-} s}$ & $\tau_{s}$ \\
& $(\mathrm{~K} / \mathrm{W})$ & $(\mathrm{s})$ & $(\mathrm{K} / \mathrm{W})$ & $(\mathrm{s})$ & $(\mathrm{K} / \mathrm{W})$ & $(\mathrm{s})$ \\
\hline 1 & 0.0027 & 0.0090 & 0.0061 & 0.0070 & 0.0046 & 48.000 \\
2 & 0.0055 & 0.0700 & 0.0126 & 0.0850 & 0.0047 & 14.600 \\
3 & 0.0022 & 0.3300 & 0.0113 & 0.4400 & 0.0011 & 2.8000 \\
4 & 0.0046 & 1.1000 & 0.0076 & 8.3000 & 0.0006 & 0.0006 \\
5 & 0 & 1.0000 & 0.0019 & 12.000 & 0 & 1.0000 \\
6 & 0 & 1.0000 & 0.0085 & 72.000 & 0 & 1.0000 \\
\hline \hline
\end{tabular}

$$
\mathrm{K}=\text { Kelvin }
$$

TABLE A. 2

COEFFICIENTS FOR CONDUCTION LOSS CHARACTERISTIC

\begin{tabular}{lcccc}
\hline \hline & $a_{0}$ & $a_{1}$ & $b_{0}$ & $b_{1}$ \\
& & & & 0.0070 \\
IGBT & 0.0027 & 0.0090 & 0.0061 & 0.0850 \\
Diode & 0.0055 & 0.0700 & 0.0126 & \\
\hline \hline
\end{tabular}

TABLE A. 3

DFIG WIND TURBINE PARAMETERS

\begin{tabular}{|c|c|c|}
\hline Quantity & Value & Unit \\
\hline Nominal turbine power & 5 & MW \\
\hline Turbine rotor radius & 63 & M \\
\hline Nominal wind speed & 12 & $\mathrm{~m} / \mathrm{s}$ \\
\hline Generator speed (syn speed) & $72-124(104.7)$ & $\mathrm{rad} / \mathrm{s}$ \\
\hline Pole pair number & 3 & - \\
\hline Rotor/stator turn ratio & 2.5 & - \\
\hline Stator phase voltage (rms) & 0.58 & $\mathrm{kV}$ \\
\hline Maximum phase voltage of RSC & 0.36 & $\mathrm{kV}$ \\
\hline Rated current of RSC (rms) & 1.12 & $\mathrm{kA}$ \\
\hline Rated phase voltage of GSC (rms) & 0.23 & $\mathrm{kV}$ \\
\hline Rated current of GSC (rms) & 1.10 & $\mathrm{kA}$ \\
\hline Nominal dc-link voltage & 1.2 & $\mathrm{kV}$ \\
\hline Switching frequency & 4.5 & $\mathrm{kHz}$ \\
\hline
\end{tabular}

\section{REFERENCES}

[1] H. Arabian-Hoseynabadi, H. Oraee, and P. J. Tavner, "Failure modes and effects analysis (FMEA) for wind turbines," Int. Journal of Electrical Power \& Energy Systems, vol. 32, no. 7, pp. 817-824, 2010.

[2] P. J. Tavner, S. Faulstich, B. Hahn, and G. J. W. van Bussel, "Reliability and availability of wind turbine electrical and electronic components," $E P E$, vol. 20, no. 4, 2011.

[3] S. Yang, D. Xiang, A. Bryant, et al., "Condition monitoring for device reliability in power electronic converters: a review," IEEE Trans. Power Electronics, vol. 25, no. 11, pp. 2734-2752, 2010.

[4] F. Blaabjerg, M. Liserre, and M. Ke, "Power electronics converters for wind turbine systems," IEEE Trans. Industry Applications, vol. 48, no. 2, pp. 708-719, 2012.

[5] C. Busca, R. Teodorescu, F. Blaabjerg, et al., "An overview of the reliability prediction related aspects of high power IGBTs in wind power applications," Microelectronics Reliability, vol. 51, no. 9-11, pp. 1903-1907, 2011.

[6] F. Fuchs and A. Mertens, "Steady state lifetime estimation of the power semiconductors in the rotor side converter of a 2 MW DFIG wind turbine via power cycling capability analysis," in Proc. EPE, 2011 pp. 1-8.

[7] M. Bartram, J. von Bloh, and R. W. De Doncker, "Doubly-fed-machines in wind-turbine systems: is this application limiting the lifetime of IGBT-frequency-converters," presented at the 35th Conf. IEEE Power Electronics Specialists, Apr. 2004.

[8] M. Bruns, B. Rabelo, and W. Hofmann, "Investigation of doubly-fed induction generator drives behaviour at synchronous operating point in wind turbines," in Proc. 13th Conf. EPE, 2009 pp. 1-10.

[9] W. Lixiang, R. J. Kerkman, R. A. Lukaszewski, L. Haihui, and Y. Zhenhuan, "Analysis of IGBT power cycling capabilities used in doubly fed induction generator wind power system," IEEE Trans. Industry Applications, vol. 47, no. 4, pp. 1794-1801, 2011.

[10] M. Musallam and C. M. Johnson, "Impact of different control schemes on the life consumption of power electronic modules for variable speed wind turbines," in Proc. EPE, 2011 pp. 1-9.

[11] A. Isidori, F. M. Rossi, and F. Blaabjerg, "Thermal loading and reliability of $10 \mathrm{MW}$ multilevel wind power converter at different wind roughness classes," IEEE Trans. Industry Applications, vol. 50, no. 1, pp. 484 - 494, Jan.-Feb. 2014.

[12] K. Ma, M. Liserre, and F. Blaabjerg, "Reactive power influence on the thermal cycling of multi-MW wind power inverter," IEEE Trans. Industry Applications, vol. 49, no. 2, pp. 922-930, 2013.

[13] T. Lei, M. Barnes, and M. Ozakturk, "Doubly-fed induction generator wind turbine modelling for detailed electromagnetic system studies," IET Renewable Power Generation, vol. 7, no. 2, 2013. 
[14] J. W. Kolar, F. C. Zach, and F. Casanellas, "Losses in PWM inverters using IGBTs," in Proc. Electric Power Applications, 1995 pp. 285-288.

[15] M. H. Bierhoff and F. W. Fuchs, "Semiconductor losses in voltage source and current source IGBT converters based on analytical derivation," presented at the 35th Annual Conf. Power Electronics Specialists 2004.

[16] O. Al-Naseem, R. W. Erickson, and P. Carlin, "Prediction of switching loss variations by averaged switch modeling," presented at the 15th Annual IEEE Applied Power Electronics Conf. and Exp., New Orleans, LA, 2000.

[17] L. K. Mestha and P. D. Evans, "Analysis of on-state losses in PWM inverters," IEE Proc. Electric Power Applications, vol. 136, no. 4, pp. 189-195, 1989

[18] U. Drofenik and J. W. Kolar, "A general scheme for calculating switching and conduction-losses of power semiconductors in numerical circuit simulations of power electronic systems," presented at the 5th Int. Conf. Power Electronics, Niigata, Japan, April 2005.

[19] A. R. Hefner, "A dynamic electro-thermal model for the IGBT," IEEE Trans. on Industry Applications, vol. 30, no. 2, pp. 394-405, 1994.

[20] SEMIKRON, SKiiP 2013 GB172-4DW V3 datasheet [Online]. Available: http://www.semikron.com/products/data/cur/assets/SKiiP 2013 GB17 2 4DW V3 20450248.pdf

[21] P. Alemi and L. Dong-Choon, "Power loss comparison in two- and three-level PWM converters," presented at the 8th Int. Conf. Power Electronics and ECCE Asia, Jeju, 2011.

[22] A. Wintrich, U. Nicolai, W. Tursky, and T. Reimann. (2011). Application manual power semiconductors SEMIKRON. [Online].Available: http://www.semikron.com/skcompub/en/SEMIKRON Application Man ual Power Semiconductors .pdf

[23] N. Mohan, T. M. Undeland, and W. P. Robbins, in Power electronics: converters, applications, and design, 2nd ed USA \& Canada: John Wiley \& Sons, Inc., 1995, p. 205.

[24] T. Lei, M. Barnes, and A. C. Smith, "Thermal cycling evaluation for DFIG wind turbine power converter based on joint modelling," presented at the Energy Conversion Congress and Exposition, Co. USA, 2013.

[25] P. E. Bagnoli, C. E. Casarosa, M. Ciampi, and E. Dallago, "Thermal resistance analysis by induced transient (TRAIT) method for power electronic devices thermal characterization. I. Fundamentals and theory," IEEE Trans. Power Electronics, vol. 13, no. 6, pp. 1208-1219, 1998.

[26] Y. Chan-Su, P. Malberti, M. Ciappa, and W. Fichtner, "Thermal component model for electrothermal analysis of IGBT module systems," IEEE Trans. Electron Devices, vol. 24, no. 3, pp. 401-406, 2001.

[27] Y. C. Gerstenmaier, W. Kiffe, and G. Wachutka, "Combination of thermal subsystems modeled by rapid circuit transformation," presented at the 13th Int. Workshop. THERMINIC, 2007.

[28] W. E. Leithead and B. Connor, "Control of variable speed wind turbines: Design task," Int. Journal of Control, vol. 73, no. 13, pp. 1189-1212, 2000.

[29] H. Sung-ho, A. Stock, and W. E. Leithead, "Controller design to avoid a range of set frequencies for a 5MW wind turbine," Industrial Control Centre, Department of Electronic and Electrical Engineering, University of Strathclyde, Glasgow,April, 2013.

Ting Lei received the B.Eng. and Ph.D. degrees from the University of Manchester, Manchester, U.K in 2010 and 2014 respectively, where she is currently a research staff.

Her research interests are wind turbine modelling, control and reliability.

Mike Barnes (M'96-SM'07) received the B.Eng. and Ph.D. degrees from the University of Warwick, Coventry, U.K. In 1997, he joined the University of Manchester Institute of
Science and Technology (UMIST, now merged with The University of Manchester), Manchester, U.K., as a lecturer, and where he is now a Professor. His research interests cover the field of power-electronics-enabled power systems and advanced drives.

Sandy Smith received the B.Sc. and Ph.D. degrees from Aberdeen University, Aberdeen, U.K in 1980.

$\mathrm{He}$ held academic appointments at Imperial College (1984-1990), Cambridge University (1990-97), Fellow of Magdalene College (1990-97) and a Visiting Professorship at Newcastle University (1998-2000). In 1997, he joined Invensys Brook Crompton as Head of Research responsible for advanced motor technologies. He is currently with the University of Manchester, Manchester, U.K., where he is a Professor. His research interests cover the field of electrical motors, generators, drives and actuators using analytical or computational electromagnetic methods.

Sung H. Hur received the B.Eng. degree from the University of Glasgow and the M.Sc. degree with Distinction and the Ph.D. from University of Strathclyde.

$\mathrm{He}$ is a Research Associate in the Department of Electronic and Electrical Engineering at University of Strathclyde. His current research interests are in control, condition monitoring and modelling, in particular with applications to wind turbines and farms.

Adam Stock received an MEng degree from the University of Newcastle Upon Tyne in 2007.

After a short spell in industry, in 2010 he took on his current role as a Research Associate with the Department of Electronic and Electrical Engineering, University of Strathclyde, Glasgow, U.K where he is also undertaking his $\mathrm{PhD}$. His research interests include increasing the flexibility of operation of wind turbines and wind farms, primarily through control.

William E. Leithead received the B.Sc. degree in mathematical physics and the Ph.D. degree in theoretical physics from the University of Edinburgh, Edinburgh, U.K., in 1971 and 1976, respectively.

Currently, he is a Professor and the Director of Systems and Control Engineering in the Department of Electronic and Electrical Engineering, University of Strathclyde, Glasgow, U.K. His research interests include power system dynamics and control and integrated design of wind turbines. 